\title{
Teaching and Learning Insight among Higher Education Students utilizing E-Tool for Game Development Subject
}

\author{
Hwei Teeng Chong, Chen Kim Lim, Kian Lam Tan
}

\begin{abstract}
There are many adapted teaching and learning (TL) practices that utilized e-learning tools to teach computer laboratories among the tertiary education students. What is the appropriate approach for TL on computing subjects catering for the current era of students? Since information and knowledge can be accessed widely and learnt from the Internet technology. Kolb's experiential learning and inquiry-based learning approaches had presented several studies area application and resulted to enrich students' hands-on learning. This research aimed to identify the teaching practices for game development related to computing skill subject. Focus is made for educators to adapt the teaching model as a method for students' learning emphasizing on software skills in developing game content. The proposed teaching models are framed as referenced from both Kolb's and inquiry-based learning theories to design the lesson plans and lab exercises. Then, a pilot test survey was conducted among the game students to retrieve their perception and experience throughout the learning process. The survey data presented students' learning are effective by watching and doing. Corresponding, the inquiry-based model is recommended for teaching practices especially to students without any prior knowledge and skills in to the computing development subject. Therefore, this research suggested both teaching approaches to strengthen students' basic knowledge learning prior to beginner level.
\end{abstract}

Index Terms: Teaching and Learning (TL) Practices, Kolb's Experiential Learning, Inquiry-based Learning, Game Development

\section{INTRODUCTION}

Teaching approaches practice have been evolving in time due to the fast innovation pace of technology creation. Utilizing computer laboratories for teaching software focusing on developing application content can be complex and tedious [12]. In this case, it has presented various areas of challenges for educators to teach innovatively to enhance students' learning especially on computer laboratories subject matter [1].

Revised Manuscript Received on June 22, 2019.

HweiTeeng Chong, Faculty of Creative Industries, UniversitiTunku Abdul Rahman, Sungai Long Campus, 43000 Kajang, Selangor

ChenKim Lim, Faculty of Art, Computing \& Creative Industry, Sultan Idris Education University, 35900 Tanjong Malim, Perak Malaysia

KianLam Tan, Faculty of Art, Computing \& Creative Industry, Sultan Idris Education University, 35900 Tanjong Malim, Perak Malaysia
It is further noted that traditional teaching method can no longer be applied into the modern classroom with the high influence of ICT use for TL in the current generation of learners where they could just access to information and obtain knowledge via internet quickly [8]. In addition, individual learning culture can differ from one another despite the students' demographic and geographic originality [5]. Therefore, TL approaches must adapt to innovation suiting up for the tech savvy generation of learners in order for them to learn effectively and develop them to be independent learners as to achieve high level of skills performance and familiarity in computer literacy. The basis of this research is to identify the teaching approaches towards students' hands-on learning for game development subject exploiting a case of game engine used for game development project. The TL content focused to teach students to develop a computer game using game engine software called Unity Technologies in lab-classroom domain. Furthermore, Kolb's experiential learning and inquiry-based learning are adapted to the teaching model to investigate on the students' learning performances. This paper motivation is to further suggest the method of teaching implementation for software tasks performance learning in the context of game development subject.

\section{LITERATURE REVIEW}

\section{Teaching and Learning Revolution}

The need to revolutionize TL had been a taboo practice around the world with the objective to produce global economist graduated people with high level of knowledge and skills. Attentively, the govern authority had spent much financial resources to develop universities by funding the digital tools for TL and researchers in the area of education development. The high influence use of computer technologies and internet technology within the tertiary education level can break accessibility barrier among students to retrieve knowledge and information [13]. Consequently, the creation of "e-learning" term was introduced that defined similarly to enhance learning performance through computing system [14]. E-learning platforms are well-known for its learning flexibility in terms of time, space, cost and domain. It has impacted and transformed the education teaching and learning practices to further enhance students' learning performance [2]. Therefore, there is a need to revolutionize TL practices from time to time to feed the generations learners to achieve the learning goals. 


\section{Challenges in Teaching Software}

Although e-learning has been widely practiced and being well-known to boost learners learning performance and engagement, there are various challenges lie ahead among educators in conducting their teaching method especially on computing skills in software application mastery [3]. Likewise, [4] also reflects on the e-learning tools and platform disadvantages for teaching by educators. Researchers recommended that the technology savvy, instructor characteristics and student characteristics can could influence the effectiveness of TL performance output. Noting on technology savvy among educators, due to the rapid growth of technology innovation resulted in the educators' requirement to attend technical training and practice progressively to self-equipped with skills and knowledge before meeting the ability to deliver computer literacy subjects. Furthermore, the learning performance of students is also dependent on instructor features in teaching to develop responsibility and motivation among the learners to achieve learning engagement. Besides that, learning style of individuals is also another challenging component. It is the present nature of people that had shown various behaviors of act in observing, examining and commenting to learning subject matter. There were many learning styles presented through article reviews writing that caters to feed various application area of subject matters [5]. In this study focusing to identify teaching model to achieve high learning performance, the core strategies of TL are referenced from both Kolb's experiential learning method imbedded with inquiry-based learning theories in the context of teaching computing application development.

\section{Learning Strategies}

[6] suggested the best practices for hands-on activities learning to perform tasks with virtual computer laboratory is by experiential learning method. It is further described to implement the experimental lessons learning exercises with Kolb's learning theory that was remodeled from John Dewey, Kurt Lewin and Jean Piget's learning models as to enhance students' learning performance and tailor for individual difference of learning style [5]. Figure 1 illustrates the connection stages of each learning cycle designed by Kolb. The learning cycle will recurrences after a completion of cycle as to advance individual learning and skills application performance.

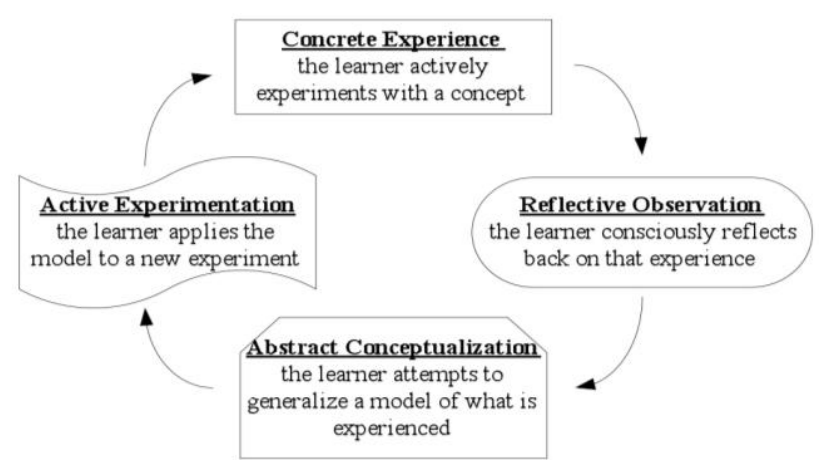

Fig. 1 Kolb's Four Stages of Learning Cycle. Adapted from [6]

\section{$\circ$ Concrete Experience (CE)}

- Description:Learners to involve practically by executing experiential learning to output experimental tasks.

- Learning Style: Accommodator and/or diverger.

- Reflective Observation (RO)

- Description: Learners to do reflection on learning by analyzing and reviewing their experiential tasks.

- Learning Style: Diverger and/or Assimilator

\section{- Abstract Conceptualization (AC)}

- Description: Learners to generate and generalizeown theories, principles or practiceswith learning experience.

- Learning Style: Assimilator and/or converger

○ Active Experimentation (AE)

- Description: Learners to attempt new learning experience plans or perform a new task with different experiential method.

- Learning Style: Converger and/or accommodator

\section{Inquiry-based Teaching}

According to [7] teaching with inquiry approach implies analyzing or acquiring process among learners whom are ambitious to know or learn more within their interest area of subject matter. Furthermore, the investigation of new info and ability to visualize acquired knowledge to form a patterns or connection within learned content requires individual to perform critical thinking, observation, experimentation, acquiring doubts and generalizing knowledge. Researchers reflected that this approach is prominent for teaching application especially for individuals with no prior to basic knowledge of subject matter acquiring learning content and skills as to enhance the speed and understanding of content learnt.In addition to findings towards supporting inquiries approach for teaching practices by [8] stated the traditional teaching approach of conducting computer laboratories courses have reflected to impaired for the needs of the modern learning domain. [6][10] recommended this approach towards hands-on activities as to further enhance student's learning performance, develop independent learners and increase learning engagement. In addition, inquiry and interactions between students or retrieving learning source from the Internet can further increase the learning performance. Besides, learning to teach can assist individuals for future self-learning and ability to construct their own knowledge [11]. Figure 2 illustrates on the structured procedure of inquiry-based designed model by [8]. This designed process implemented will act as referenced to the planned teaching concept model.

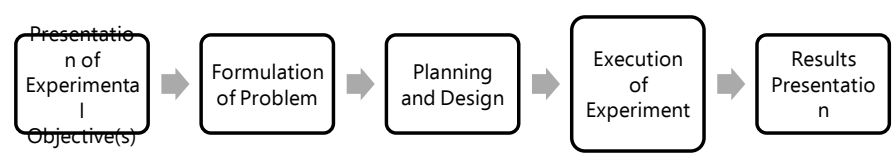

Fig. 2 Inquiry-based Implementation Process. 


\section{TEACHING FRAMEWORK}

\section{Conceptual Model for TL}

Table 1 presents on the learning plans for students to perform their learning tasks. This is to determine the participated students learning style and later to analyze their performance. The practical component is explained on the steps to be taken based on the stages for one complete cycle for all the learning modules as planned by the instructor.

Table. 1 Experiential Learning Plans with Adaption of Kolb's Learning Strategies.

\begin{tabular}{|c|c|}
\hline & Practical Components \\
\hline $\begin{array}{c}\boldsymbol{C E} \\
\text { [Feeling \& } \\
\text { Doing, Feeling } \\
\text { \& Watching] }\end{array}$ & $\begin{array}{l}\text { 1) Watching video tutorial } \\
\text { presented by instructor } \\
\text { 2) Performing learning task with } \\
\text { instruction that is demonstrated phase to } \\
\text { phase } \\
\text { 3) Producing and outputting } \\
\text { learning task at the end of } \\
\text { demonstration }\end{array}$ \\
\hline $\begin{array}{c}\boldsymbol{R O} \\
\text { [Feeling \& } \\
\text { Watching, } \\
\text { Thinking \& } \\
\text { Watching] }\end{array}$ & $\begin{array}{l}\text { 1) Analyzing learning } \\
\text { components } \\
\text { 2) Discuss and comparelearning } \\
\text { components among peers } \\
\text { 3) Specify the connection and } \\
\text { contrary of learning components }\end{array}$ \\
\hline $\begin{array}{c}\boldsymbol{A C} \\
\text { [Thinking \& } \\
\text { Watching, } \\
\text { Thinking \& } \\
\text { Doing] }\end{array}$ & $\begin{array}{l}\text { 1) Perform cognitive thinking on } \\
\text { learning components by comparing } \\
\text { earlier performing task and after } \\
\text { discussion performing task. } \\
\text { 2) Explains and note down on the } \\
\text { advantages and disadvantages of both } \\
\text { tasks performed. } \\
\text { 3) Generating relevant principles, } \\
\text { theories or mechanism on learning } \\
\text { components. }\end{array}$ \\
\hline $\begin{array}{c}\boldsymbol{A E} \\
\text { [Thinking \& } \\
\text { Doing, Feeling } \\
\text { \& Doing] }\end{array}$ & $\begin{array}{l}\text { 1) Perform combination of } \\
\text { learning task without instruction } \\
\text { demonstration following phase to phase. } \\
\text { 2) Recording performed task for } \\
\text { presentation } \\
\text { 3) Prepare for new concrete } \\
\text { learning experience by performing new } \\
\text { tasks with new advance method. }\end{array}$ \\
\hline
\end{tabular}

On the other hand, educators are responsible in performing inquiry-based approachinto students' experimental lesson learning to observe the students' learning performance and achievement. Figure 3 shows on the five stages practice for instructor as a criterion to design teaching plan for conducting the lessons in lab-classroom utilizing e-learning tool. Further description is explained accordingly. First, demonstration phase involved instructor to perform lectures on theory or principles and basic demonstration of learning subject matter. Next on the same phase requires the instructor to present video learning content and enquire students to learn by watching the video. While watching the video, students are required to perform the tasks as presented. As for the inquiry's compilation phase, instructor is to note the students on the goals to achieve at the end of each learning component. This phase, instructor acts as the main assistant and facilitator in students' learning. Students are also encouraged to seek assistant among their fellow classmates or the internet source. Subsequently on development planning, instructor is to assign a major project development and enquire students to propose their project development methods and content. Instructor will further provide feedback on the presented proposal in the same stage to further enhance students' knowledge on subject matter. Thereafter, development execution phase involves students' progress observation and facilitation performed by instructor. Furthermore, instructor is to query on students' performing tasks methods in results to project output within the learning context. The last phase on conclusion requires students to present their project output and write a report on their project development. Then, the instructor continues to feed advices on the project output as to further extend students' knowledge and skills in performing tasks. This phase also follows up with students' performance evaluation to determine the effective of learning method with inquiry-based teaching.

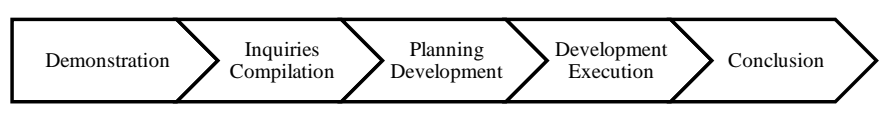

\section{Fig. 3 Teaching plansbased on inquiry-based approach procedures.}

\section{METHODOLOGY}

\section{Introduction}

This research adapts practical use of game engine software(Unity Technologies) into teaching game development modules and is performedin the computer laboratory classroom (refer to figure 4(a)). Instructor went through the teaching concepted model for a semester of 14 weeks with undergraduate students whom have no prior knowledge and skills to the Unity Technologies game engine. Furthermore, the selected instructor should meet criteria of having years of experience and sufficient level of knowledge to be able to teach the subject as to cater for students' inquiries. Besides, sample of selection are selected based on convenient samples that derived from UniversitiTunku Abdul Rahman (Sg. Long Campus). Individuals that involved are one instructor that is assigned to teach the subject of game development and 27 undergraduate students that are registered to the game development subject studies for that one entire semester. Students that are taken into participation must finish all 14 weeks study to be part of the research scope. Moreover, the students should all be undertaking the same bachelor's degree studies and majoring in game design.

\section{Research Design}

This research was conducted by pilot testing on the teaching model as in figure 3 by instructor and learning

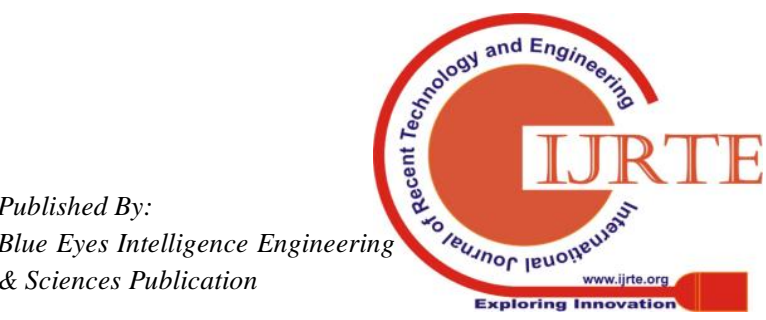


model application as in table 1 performed by the students. Data analysis is done by observation studies performed by instructor in lab classes (refer to figure 4(b)) where students are observed performing on one of the given lesson tasks. In addition, observation is also done by previewing all students lesson performance through their submitted technical portfolio reports on every end of each lesson to determine whether students are achieving the lesson objective. Next, feedbacks form is collected by distributing survey questionnaire to the students at the end of the semester for participation. The data is collected via online Google Form (https://goo.gl/forms/JuRqLLRzTLyK7idH2) for further data analysis and discussion. Survey questionnaires are designed based on the learning model practical component activities to identify students' learning style. Feedback data is studied and concluded in conclusion.

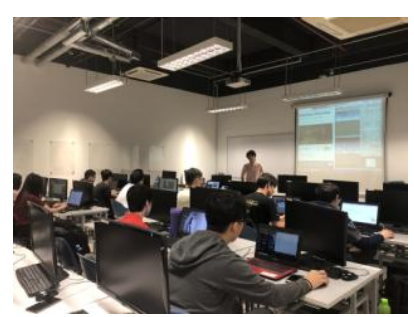

(a) Lesson conducted in lab classroom with the present of instructor for inquiries after demonstration stage.

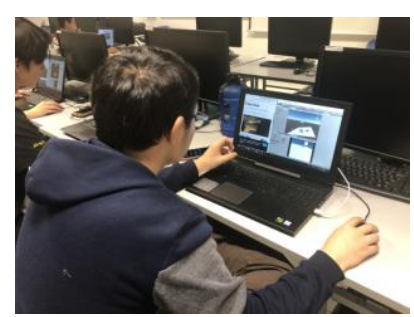

(b) Observation by instructor during a lesson in lab classroom.
Fig. 4 Observation Studies

\section{DATA COLLECTION \\ RESULTS}

The results of data collection areshown in figure 5(a) to (o). Questionnaires are designed to obtain perception on students' learning styleand performanceas referenced from Kolb's four stages of experiential learning cycle model. Figure 5(a) to 5(e) results explained on whether students'learning approach is effective with CE. Next, figure 5(f) to 5(h) describes RO learningresults. Then, AC learning feedbacks derived from results illustrated on figure 5(i) to 5(k). Lastly, figure 5(1) to 5(o) shows AE learning performance results. Overall analysis is further discussed in section 5.2.

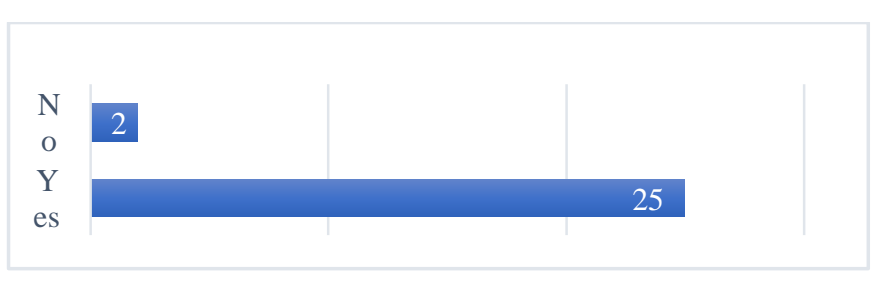

(a) Do you think learning through video is helpful to you?

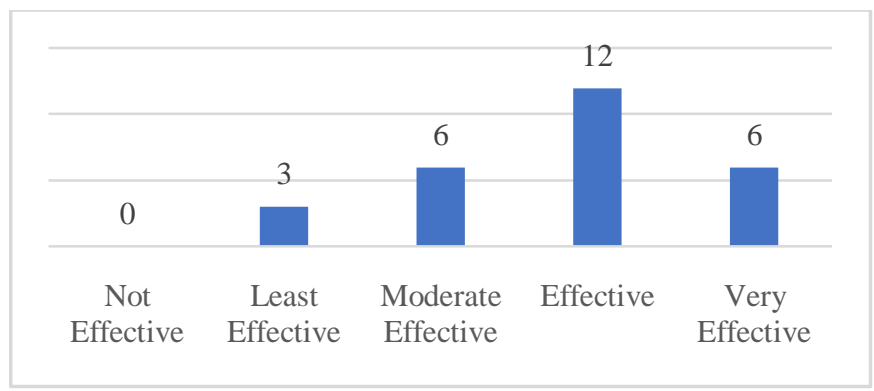

(b) How do you rate the effectiveness of learning through video tutorial?

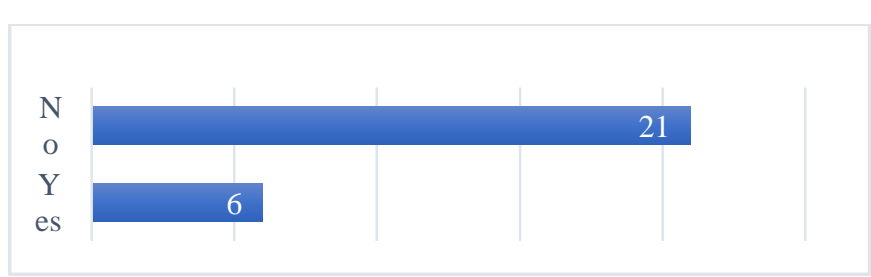

(c)Do you find it difficult tofollow the video tutorial during your learning process?

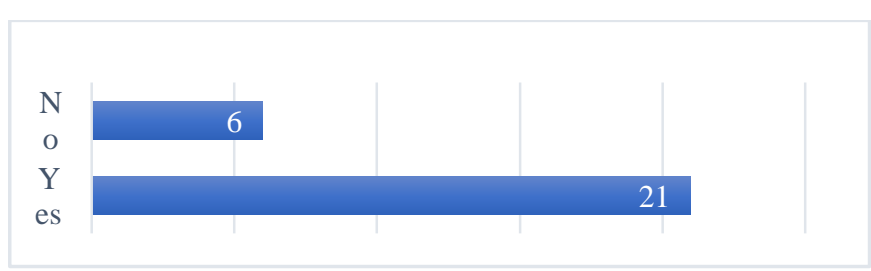

(d)Were you able to achieve your learning objective at the end of the video tutorial?

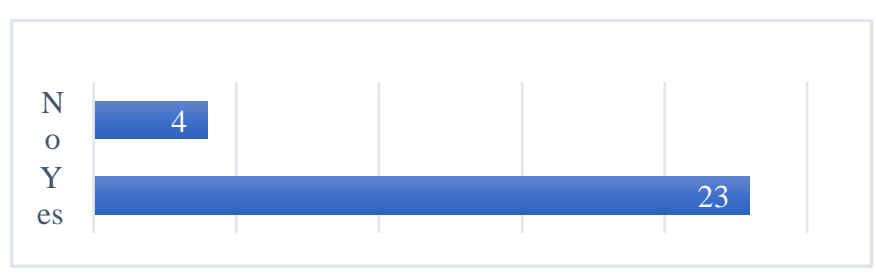

(e)Do you think by watching video tutorial is enough for you to learn and output your learning objective?

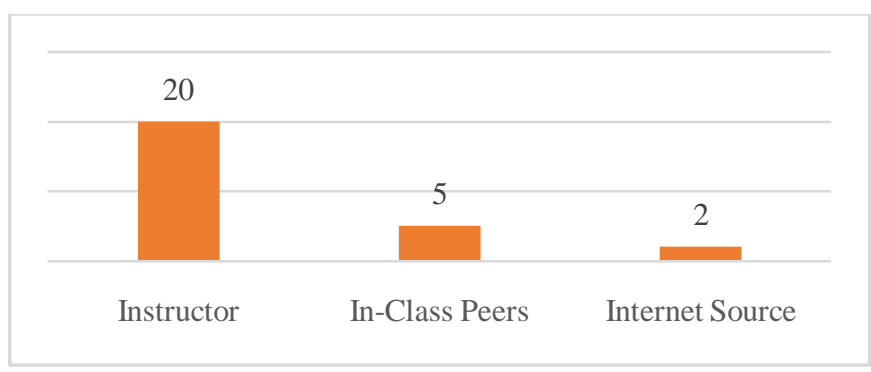

(f)Who do you prefer most to inquire for assistant to help you understanding further on your learning subject? 


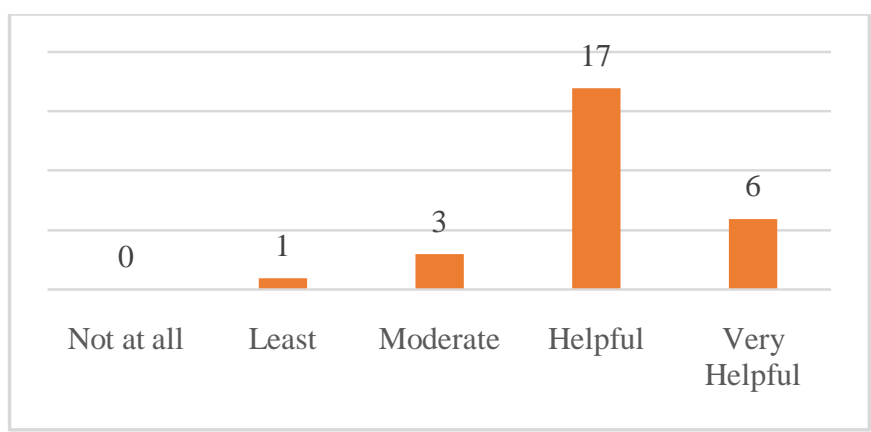

(g)How would you rate your chosen source of assistant towards the level of helpfulness in assisting you to achieve your objective?

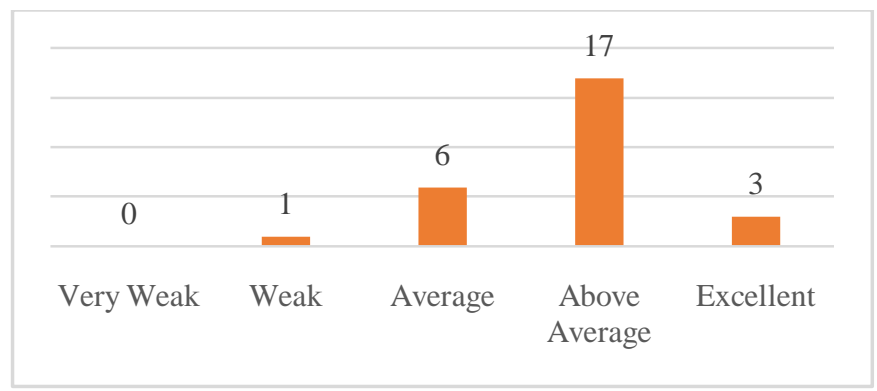

(h)Rate your ability using game engine to re-produce learning objective with different techniques using internet source and video tutorial.

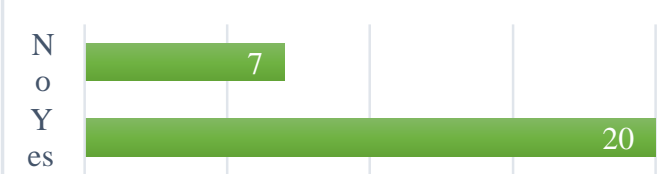

(i)Can you identify and determine which tools or features in game engine to use to produce your game development project?

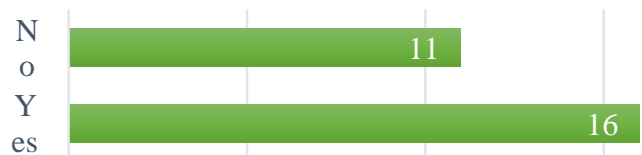

(j)Will you be able to identify the best approach to perform tasks in order to achieve game development project objective?

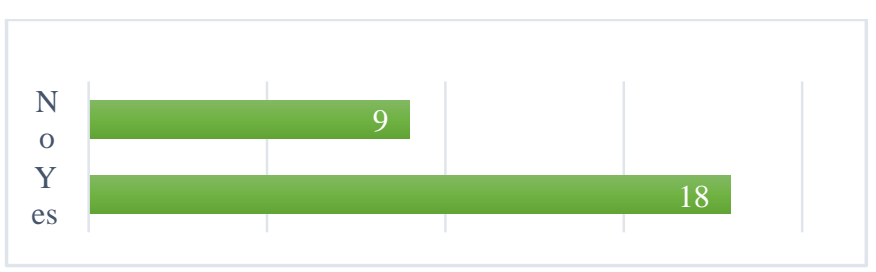

(k)Will you be able to apply what you have learnt to achieve the game development project objectives?

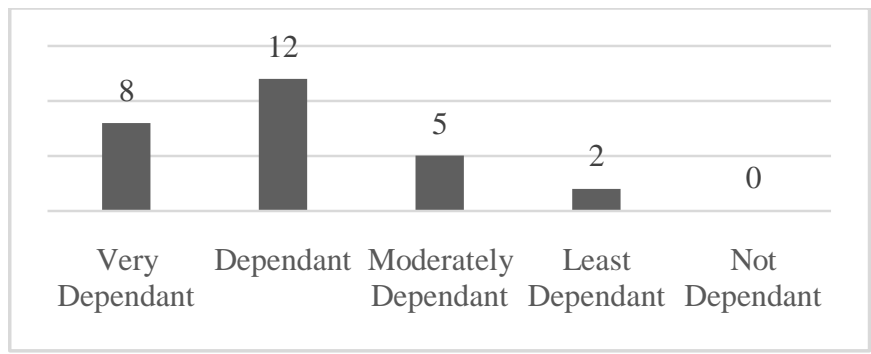

(l): Rate your dependency of video tutorial to perform your game development project.

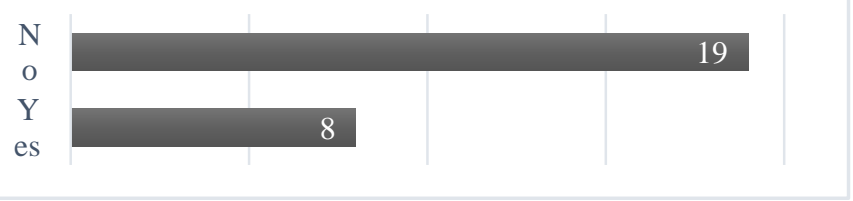

(m)Can you identify all the game engine components you used in your game development project?

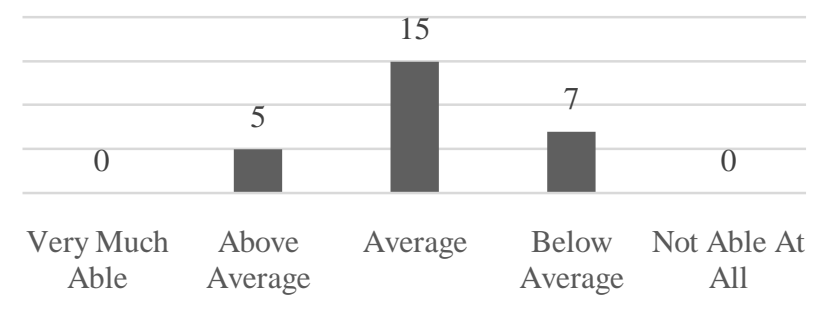

(n)If you are given a new titledproject development to perform, how much do you think you can perform?

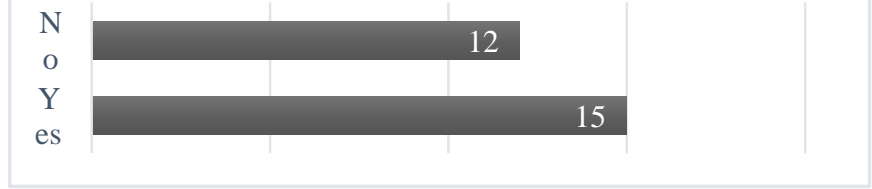

(o)Did you record down all your learning process for further references?

\section{Fig. 5 Questionnaires and Data Results}

\section{Overall Analysis}

Obtained data are analyzed and results are discussed in Table 5.1. 
Table. 2 Students' Performance

\begin{tabular}{|l|l|}
\hline Learning Stage & $\begin{array}{l}\text { Analysis Results of Learning } \\
\text { Approach }\end{array}$ \\
\hline $\begin{array}{l}\text { Concrete } \\
\text { Experimentation }\end{array}$ & $\begin{array}{l}\text { High level performance in doing } \\
\text { learning approach. }\end{array}$ \\
\hline $\begin{array}{l}\text { Reflective } \\
\text { Observation }\end{array}$ & $\begin{array}{l}\text { Low level performance in watching } \\
\text { learning approach.Students is very } \\
\text { dependent to inquire a lot ofassistant. }\end{array}$ \\
\hline $\begin{array}{l}\text { Abstract } \\
\text { Conceptualization }\end{array}$ & $\begin{array}{l}\text { Moderate level of thinking in learning } \\
\text { towards understanding game engine } \\
\text { structure in learning approach. }\end{array}$ \\
\hline $\begin{array}{l}\text { Active } \\
\text { Experimentation }\end{array}$ & $\begin{array}{l}\text { Low level performance to apply new } \\
\text { experiment in learning approach. }\end{array}$ \\
\hline
\end{tabular}

\section{VI.CONCLUSION}

As a conclusion, the students learning style towards software application on content development has been identified and teaching method to evaluate students learning performance has also been investigated. Results have suggested on teaching game engine software to undergraduate students whom have no prior basic knowledge, demonstrated the effective learning approach of experiential lesson by watching and doing in order to enhance their learning performance and knowledge for future applications. In additional, the presents of instructor, peers and internet source for inquiry assistant will also enhance their learning towards better understanding upon the whole learning modules. Besides, observation on students whom are very engaged and responsible to their learning achieve high level of performance in which they presented ability to learn and also teach their peers in executing knowledge and skills learnt. Nonetheless, the learning culture may differ depending on demographic, psychographic and geographic originality of individuals. Furthermore, observed case study had also displayed the need to enhance students learning by enabling them to think perform independent cognitive thinking in order for them to apply all their learning into executing new experimental tasks.

\section{LIMITATION \& FUTURE WORK}

The results of this research based on studywere limited by the small number of student intakes of learning subject. An increase in number of student intake would allow more accurate results into statistical comparison to provide significant difference of learning style. Research may also vary from student intake dependent to students' motivation and interest towards completing their game design degree studies. In this scenario, a filtration to select students' participation by considering their course grades or result of CGPA 3.0 and above as to be considered as having his/her tendency in being motivated and interest to learn and achieve high grades in game development subjects.

As for future TL method research implementation, it is vital to consider problem-based TL approach to advance level of students' knowledge and further develop their skills in critical thinking to achieve higher performance of knowledge and skills application in computer literacy.

\section{ACKNOWLEDGMENT}

The authors would like to acknowledge the many helpful suggestions of the anonymous reviewers, UniversitiTunku Abdul Rahman for the financial support for paper publication and conference, Ms Natalya RudinaShamsuar for supervising the whole research progress and all the students for their participation in this research.

\section{REFERENCES}

1. Mauricio, R., Veado, L., Moreira, R., Figueiredo, E., \& Costa, H. (2018). A systematic mapping study on game-related methods for software engineering education. Information and software technology, 95, $201-218$

2. Sife, A., Lwoga, E., \& Sanga, C. (2007). New technologies for teaching and learning: Challenges for higher learning institutions in developing countries. International journal of education and development using ICT, 3(2), 57-67.

3. Voogt, J., Erstad, O., Dede, C., \& Mishra, P. (2013). Challenges to learning and schooling in the digital networked world of the $21 \mathrm{st}$ century. Journal of computer assisted learning, 29(5), 403-413.

4. Islam, N., Beer, M., Slack, \& Frances. (2015). E-learning challenges faced by academics in higher education. Journal of education and training studies, 3(5), 102-11.

5. Durmuscelebi, M. (2013). Examining candidate teachers' learning styles by some variables. International journal of academic research, 5(3), 210-219.

6. Konak, A., Clark, T., \& Nasereddin, M. (2013). Best practices to design hands-on activities for virtual computer labotories. 3rd IEEE integrated STEM education conference (ISEC) (pp. 1 - 7). Princeton, NJ: IEEE.

7. Shamsudin, N. M., Abdullah, N., \& Yaamat, N. (2013). Strategies of teaching science using an inquiry based science education (IBSE) by novice chemistry teachers. 6th International conference on university learning and teaching (InCULT 2012) (pp. 583-592). Selangor, Malaysia: Elsevier Ltd.

8. Buch, N. J., \& Wolff, T. F. (2000). Classroom teaching through inquiry. Journal of professional issues in engineering education and practice, 105-109

9. Ma, C., Xiao , R., Wei, Y., \& Yang, H. H. (2011). An inquiry-based learning approach on a educational technology course. 2011 International symposium on IT in medicine and education (ITME) (pp. 422-424). Cuangzhou: IEEE.

10. Justice, C., Rice, J., Warry, W., Inglis, S., Miller, S., \& Sammon, S (2007). Inquiry in higher education: Reflections and directions on course design and teaching methods. Innovative higher education, 31(4), 201-214.

11. Biswas, G., Leeelawong, K., Schwartz, D., Vye, N., \& The Teachable Agents Group at Vanderbilt. (2005). Learning by teaching: A new agent paradigm for educational software. Applied artificial intelligence, 19(3-4), 363-392.

12. Dubinsky, Y., \& Hazzan, O. (2005). A framework for teaching sofware development methods. Computer science education, 15(4), 275-296.

13. Selwyn, N. (2007). The use of computer technology in university teaching and learning: A critical perspective. Journal of computer assisted learning, 23(2), 83-94.

14. Welsh, E., Wanberg, C., Brown, K., \& Simmering, M. (2003). Elearning: Emerging uses, empirical results and future directions. International journal of training and development, 7(4), 245-258. 